\title{
Customer data management in practice: An insurance case study
}

Received (in revised form): 28th April, 2003

\section{Edith N. Pula}

is Asset Solutions Specialist in the Financial Services Solutions Centre of IBM Global Services. She has over 20 years' staff and consulting experience in all lines of insurance, with an in-depth emphasis on IT solutions across financial services. She has extensive skill and experience in developing systems for insurance product development, new business, policy administration, data integration and information analysis, software package evaluation and financial analysis of business operations.

\section{Merlin Stone}

is IBM Professor of Business Transformation at the University of Surrey (part-time). He is also part-time Business Research Leader with IBM's Business Consulting Services, where his role combines consulting and marketing with the development of business research partnerships with IBM's clients, partners and universities. He is a director of QCi Ltd., an Ogilvy One company which specialises in customer management consulting, assessment and supplies, the Customer Management Assessment Tool (CMAT, software and benchmarks for assessing a company's CRM performance) and of The Database Group Ltd, suppliers of customer base management services.

\section{Bryan Foss}

is leading an IBM business providing and integrating application-based CRM solutions for retail banks and other financial services companies worldwide. Typical B2C and B2B projects have included pragmatic customer management consulting, data warehouse and marketing database build, data analysis and data mining for customer segmentation and scoring, profitability and risk management (including Basel II) and integrated customer campaign communications, including contact centre, web and mobile e-business through direct and intermediated channels.

\begin{abstract}
This project describes how a large insurance company addressed the issues involved in assessing and improving the quality of its customer data. New business capabilities needed to be delivered to time and budget, despite the discovery of inadequate data quality in the numerous data sources required. This case study demonstrates the application of many of the principles covered in the authors' previous two papers.
\end{abstract}

\section{BUSINESS BACKGROUND: ACHIEVING RETURN ON INVESTMENT FROM CRM PROJECTS}

The authors' research shows that customer relationship management (CRM) projects can achieve higher rates of return by work on data quality. Existing and new data need to be integrated and shared, with updates synchronised among many different systems. These systems (including operational, analytical and customer contact applications and databases) were rarely designed to work together and the data they collect and use are not normally collected, structured or quality-assessed for the CRM purposes for which they are eventually used. Financial services and other companies around the world face these data quality and integration issues.

This case study describes a real (but anonymous) US financial services project, 
with conclusions and learning points supported by detailed findings, which are typical of many types of CRM, business intelligence (BI), compliance (eg Basel II or anti-money laundering) and other data integration projects. The Data on Demand offering from the authors' company (the consulting company) applies these reusable techniques to the acceleration of integration and improvement of return on investment for complex and multistage projects, which rely on exploitation of existing business data, including:

- consolidation of administrative and other production systems

- addition and integration of new CRM application systems (including Siebel and most others)

- development of customer or partnership-centric views and operational databases (such as the Client Information Integration Solution (CIIS)) ${ }^{1}$

- development of BI systems, data warehouses and marts (such as the Banking Data Warehouse ${ }^{2}$ and within the Basel II and anti-money laundering compliance projects)

- development of internal or value-chain transaction and data linkages, whether carried out through real time, asynchronous or batch connectivity and messaging hubs (such as Websphere Integration Services, MQSeries ${ }^{3}$ or Ascential Software's Datastage toolset).

Data quality assessment and analysis are crucial to projects that rely heavily on the re-use of data from existing operational systems. This assessment is often done 'by hand', with data fields analysed one by one with separately developed assessments using utilities or even hand-written programming code. Assessing data quality in this manner can require an effort of three to five hours per attribute and calls for the work of valuable - and expensive - system professionals. Even then, many errors are easily overlooked. Those doing the work may not know enough about the data to enable them to quantify and assess all anomalies. Only by concentrating on the crucial analysis phase of a project can the transfer of inappropriate or irrelevant data be prevented. Without this, companies can be led to the syndrome of "code, load ... and explode', as issues are often discovered far too late, causing project and cost overruns, return on investment (ROI) case failure and even project cancellation or abandonment.

\section{CASE STUDY INTRODUCTION}

Most financial services companies know that the key to successful marketing lies in their data. Possessing the data, however, is just the first step in a successful marketing effort. Customer data must be analysed to identify which customers are likely to purchase a specific product, which customers will return a profit sooner and which customers will remain customers. This data analysis may then be merged with market research to forecast customer behaviour and also their financial needs, and to match them to a company's products.

The insurance industry acknowledges the critical importance of understanding customer behaviour. However, there is still a fundamental lack of knowledge and comprehension in this area. Some of this is due to insurance companies' computer systems being based on policy and product information and not on customer information. The need for transactional processing and operational efficiencies created this focus, for very good reasons. Today's systems, however, allow them to exploit customer information in new ways. 
Market pressures and competition are forcing insurers to become increasingly focused on segmenting their customer base and retaining profitable customers. To help them do this they are capturing more customer information and using it to build business intelligence systems to support cross-selling and retention processes.

Like any modern financial services company, InsureCo (the fictional name of the US subsidiary of a real multinational financial services client) faces this challenge. To meet the challenge, InsureCo is creating customer-centredness using the enormous data set it already has. However, the company requires meticulously accurate and profoundly reliable data to be able to use them to manage customers. InsureCo's business units need information they can use with utmost confidence to make actionable and potentially business-altering decisions.

\section{THE PROJECT}

InsureCo engaged the business intelligence practice of the consulting company to take its data and to develop ways and means of acting on them. These data were processed at a centre which focuses on developing practical solutions to complex integration issues and deploying them through highly scalable proofs-of-concept. In this case InsureCo's data were processed on the consulting company's database software, scalable servers and managed storage. The project team, a compact combination of the consulting company and InsureCo staff, designed much of the analysis and data definitions at InsureCo's head office. While the consulting company provided experienced business intelligence project management and data modelling skills, InsureCo provided in-house business and data knowledge. Evoke Software supplemented these skills with data-profiling capabilities.
The effort generated several data-driven analytical pieces of work, including:

- a product management data mart to enable analysis of products, customers and agents based on financial performance, profit and cost

- a statistical loss model for customer profitability analysis

- a customer management data mart to enable analysis of customers, products and agents based on segments and scoring

- analysis of existing books of business to understand customer profiles based on demographics, lifestyle and risk information

- customer segments that match the demographic profiles

- scoring models for cross-selling auto insurance to homeowner product owners and homeowner insurance to auto product owners.

A BI solution was designed to satisfy two needs - immediate informational reporting and data mining techniques to segment InsureCo's customer data and integrate them with external data. The results were the ability to score, model and implement a customer cross-sell pilot.

Before this end result could be achieved, however, much foundation work had to be done, including:

- validating and installing the necessary hardware and software configuration

- data modelling (or data model customisation) to map data to the way the business runs

- extracting data from source systems and performing transformations, cleansing and matching of customers to households.

InsureCo's investment in this project was substantial, not just in time and money 
spent, but also in the effort to ensure a return and results. This is not 'business as usual', but a major step towards doing business in new and very different ways. Imagine what might happen if all the complex analytics were based on inaccurate data. The risk of using spurious data is spurious results. Just imagine the cost impact when bad data lead an insurance company to abandon the wrong product line or to pursue the wrong kind of customer.

\section{DATA ASSESSMENT IS A CRITICAL YET DIFFICULT STEP}

In a large company like InsureCo, customer data are spread across dozens of different systems and are usually inconsistent between those systems. This situation develops over many years through mergers and acquisitions and the development of product-structured or silo businesses. It is very hard and sometimes impossible to obtain a single view of each customer in this situation. InsureCo, like most insurance and financial services companies, wants a 'common customer view' — in this case for marketing analytics and risk management. Despite the enormous number of data InsureCo has about its customers and about their behaviour, achieving this view is almost impossible if one relies on current data structures and on the business processes that use them. Most corporate data are plagued with inconsistencies and with quality issues that are only discovered when an attempt is made to use them for new purposes or to transform them into meaningful information.

\section{HOW TO SOLVE THE DATA PROBLEM}

The problem has a solution. The software used, from Evoke Software, is a tool that offers an innovative, unmatched solution that is specifically designed to accelerate the integration, migration and consolidation of corporate data. It enables a company to understand fully the content and structure of its corporate data. It is driven by mathematical models and techniques developed over many years through business experience and in conjunction with university research. It examines the data in valid sample sets or in their entirety - rather than relying only on using metadata or copybooks which while useful, are generally inadequate or even misleading. It enables data analysts to understand the content, structure, relationships and quality problems they need to address to ensure successful data integration, migration or consolidation. Project managers use these products to manage the workflow process of identifying and resolving data issues, capturing and communicating knowledge about source data and tracking individual action items during development.

This software provides a set of tools that automates the discovery of valuable information about corporate systems by identifying hidden data quality issues and inconsistencies between different systems. It does this by analysing and 'profiling' data sources to discover their content structure and quality. Several products work in concert:

- Import extracts and prepares data from Relational, Virtual Storage Access Method and IMS data sources for data profiling

- Source Profiler examines source data within and across systems in order to establish the content, quality and structure of those source data

- Repository stores information developed with Source Profiler and makes this information available for other of the software provider's 
products and for third party data cleansing, movement and integration products

- Design helps design staging and target databases, particularly where no target structure is yet defined or that target's design is not yet stable

- Fixed Target Mapping (FTM) maps the profiled data sources to existing structures such as custom data warehouses, IBM data warehouse, the CIIS, packaged application data structures such as customer relationship management and enterprise resource planning systems, e-commerce applications and Enterprise Application Integration middleware solutions

- Repository Navigator provides a user-friendly interface for easy access to all information in the Repository.

The above software was used in this project for:

- data preparation: in the data preparation phase, Source Profiler and Import for Relational, Virtual Storage Access Method and IMS are used to access and, as appropriate, extract data from source systems and prepare them for profiling. Data may be imported from most types of legacy systems as flat files. When the source data are from COBOL applications, the documented data layouts (copy books) are captured and validated using Source Profiler

- data profiling: during the data profiling phase, data are analysed in three dimensions - down columns, across rows and between tables to produce a fully normalised model of the source data. The data description created is referred to as Meta Data (as it is a description of data content and formatting).

Profiling is an interactive process in which the results are reviewed in a business context to arrive at a model that is both fully consistent with the source data and completely accurate as to business meaning. The results of data profiling are stored in the Repository for reuse

- data mapping and design: the data mapping and design phase uses information from the Repository, captured during data profiling, to generate transformation maps to the target databases. Where required, the design phase assists in creating new databases that are fully compatible with the source systems. The design process starts with the normalised model created during data profiling, it supports model enhancements and denormalisation to suit target requirements and produces data definition language for the new target, as well as source-to-target transformation maps. For existing target applications, Fixed Target Mapper captures target data structures from packaged applications or data warehouses and manages the mapping process from the previously profiled sources to the captured target definition or Extensible Markup Language Data Transmission Document. The mapping process ensures that all data type inconsistencies are resolved and that cleansing and transformation specifications are defined.

\section{THE SAVINGS}

The most obvious savings from applying data profiling to a project like InsureCo's is accelerating the project timeline.

However, given the controlled Application Service Provider (ASP)-like model used in this project, the projected actual savings in time did not make a significant difference in this first phase 
alone. This was because IBM's ASP-like model already provided substantial productivity gains at this phase of the process, which had already been assumed in the committed timescales and project costing to InsureCo. The benefit of most importance to InsureCo at this and later stages was in making data discoveries that led to a greater understanding of data sources and therefore led to better data for feeding the BI systems. This facilitated savings in time, potential cost of rework and project risk in later phases.

\section{APPLYING THE DATA}

The first project objective was to perform data mining to determine a customer's propensity to buy car insurance, given certain extracted and derived facts including how much life insurance a customer already owned. Data to be used in the mining had been extracted from the source systems without any in-depth data assessment, under the tacit assumption by InsureCo management that the quality was good enough to reach the project business goals. The team profiled the data with the Software to test these assumptions, knowing that much of the data had been moved to a new system during a conversion three years earlier and that little true cleansing had been done then. InsureCo's lead data analyst told the team that, "All converted data was brought over "as is" unless it had been coded to support pricing'.

The team used a sample of 10,000 records from each file extracted for the data mining - car, homeowners, agent, property structure, client and life. In practice, the Software can profile entire data sets if desired. Sample data were used from a number of states, reflecting the different sizes of customer base in each.
The automated profiling itself took just under 23 hours to execute against hundreds of millions of rows of data (3.7 minutes per attribute). During the initial review, the team's two lead analysts reviewed the Column Profiling results for 239 attributes in less than three hours. This is a considerable acceleration over traditional methods.

Some sample results included those relating to 'roof year' (the date that a new roof is put on a building). In US insurance this is an important risk factor that represents the recency of roof replacement, which is a regular occurrence, involving local roofing types and materials. Findings included:

- 7 per cent of the 'roof year' records contained NULL values (no data recorded)

- default values of '1900' and '1908' were used in many records (perhaps a system or data entry default)

- nearly two-thirds (65 per cent) of the values were '1997'. In discussing these strange results with a business analyst, the team found that during a major data file conversion in 1997, any record containing either no value or a roof year default value that was equal to the building construction year was assigned a conversion default value of '1997' because InsureCo had not wanted to penalise customers for its probable lack of correct information on the age of the roof

- new records in the file were assigned a 'roof date' value based on varying and inconsistent business rules

- the new system (introduced in 1997) was presumed to have very high data quality because of its relative age. The team instead discovered it had the same poor quality as the other, much older, source files as data quality had not been assessed or improved during system migration. 


\section{Customer data management in practice: An insurance case study}

Table 1: Results relating to 'roof years'

\begin{tabular}{|c|c|c|}
\hline Data element & Findings & Analysis and comments on intended use of data \\
\hline $\begin{array}{l}\text { Square } \\
\text { footage }\end{array}$ & $\begin{array}{l}1,331 \text { records out of } 10,000 \\
\text { have the value } 983 \text { square feet. }\end{array}$ & Seemed unusual, is there an internal default? \\
\hline Birth date & $\begin{array}{l}\text { Domain range included many } \\
\text { values from } 1600-1800 ; 30 \text { per } \\
\text { cent were NULL; many dates } \\
\text { have year values greater than } \\
\text { current date; many values were } \\
\text { blank. }\end{array}$ & $\begin{array}{l}\text { If the birth date was not needed for pricing, as in birth } \\
\text { date for pricing homeowners' policies, there were few } \\
\text { or no entries. }\end{array}$ \\
\hline Gender & $\begin{array}{l}\text { Gender domain values included } \\
\text { M, F, NA and } 44 \text { per cent were } \\
\text { blank. }\end{array}$ & $\begin{array}{l}\text { Gender was identified as a critical data item for } \\
\text { propensity scoring. }\end{array}$ \\
\hline First name & 25 per cent blank values. & \\
\hline $\begin{array}{l}\text { Occupation } \\
\text { code }\end{array}$ & $\begin{array}{l}80 \text { per cent of entered values } \\
\text { are default; } 40 \text { per cent blank. }\end{array}$ & $\begin{array}{l}\text { Occupation code was identified as a critical data item } \\
\text { for propensity scoring. }\end{array}$ \\
\hline Miles driven & All values were $4, \mathrm{~N}$ or blank. & $\begin{array}{l}\text { Prompted the question: is the column label accurate to } \\
\text { the data meaning? What importance and purpose has } \\
\text { this data item? }\end{array}$ \\
\hline $\begin{array}{l}\text { Policy } \\
\text { description }\end{array}$ & $\begin{array}{l}\text { Many values did not seem } \\
\text { consistent with the book of } \\
\text { business. }\end{array}$ & \\
\hline $\begin{array}{l}\text { Reason for } \\
\text { cancellation }\end{array}$ & Found 67 distinct values. & $\begin{array}{l}\text { Domain set was non-standard across input means - } \\
\text { ie there was no consistency in data entered as 'reason } \\
\text { for policy cancellation'. As a result it would have been } \\
\text { impractical to carry out a quantitative analysis on this } \\
\text { data item - although qualitative text comment might } \\
\text { be some use in support of analysis. }\end{array}$ \\
\hline $\begin{array}{l}\text { Additional } \\
\text { coverage } \\
\text { (product cross- } \\
\text { holdings) }\end{array}$ & $\begin{array}{l}\text { Value incidence was much } \\
\text { lower than expected for } \\
\text { households. }\end{array}$ & $\begin{array}{l}\text { From a sales campaign perspective this means that } \\
\text { households had a lower product density (number of } \\
\text { products per household) than expected. The sales } \\
\text { campaign was a cross-selling exercise and the product } \\
\text { density was expected to be at least between } 1 \text { and } 2 \text {. } \\
\text { However, using Evoke Software the project team } \\
\text { discovered this is not the case. The risk was that the } \\
\text { corporate cross-selling initiative might not be } \\
\text { supported by existing data. }\end{array}$ \\
\hline $\begin{array}{l}\text { Agent } \\
\text { identifier }\end{array}$ & $\begin{array}{l}\text { Higher than expected number of } \\
\text { invalid agent identifiers. }\end{array}$ & $\begin{array}{l}\text { Agent identifier was a key piece needed in the data } \\
\text { mining process, invalid agent identifiers would } \\
\text { invalidate a large percentage of the data mining } \\
\text { results, undermining any possibility of analysis of the } \\
\text { impact of individual agent, agent type or agent } \\
\text { change. }\end{array}$ \\
\hline Amount paid & $\begin{array}{l}\text { Many values were negative or } \\
\text { very large positive. }\end{array}$ & Data were not within reasonable limits. \\
\hline
\end{tabular}

These results were very surprising to both information technology management and to data analysts who had wrongly assumed that data quality was high. Fortunately, a business user subject matter expert could explain many of these unexpected results from her memory of a major data conversion to the new system that had taken place years before. From all the fields in question, only the fields relating to determining a correct premium rate were found to be of reasonable data quality. A senior analyst stated that use of the software had confirmed that 'the Emperor has no clothes' - data that were believed by management to be sufficiently close to being completely accurate were not. Insure Co team members commented: 'there is a 
(growing) consensus that the quality of the InsureCo data is consistent consistently bad'. If not corrected, the outcome would significantly affect InsureCo's readiness for its planned marketing campaigns that were tied to very specific sales initiatives. Table 1 contains more results.

Using the software provider's redundancy profiling, the teams compared two household identifiers from the fire and home-owners' systems: fire, household number and homeowner, household number. The teams found significantly low overlap between the domains of values including different minimum and maximum value ranges per attribute. There appeared to be a big gap in the starting values for the attributes, for example, 0999947429 versus 1500085501 . This is a key data integration issue, because agent and policy subject areas must be connected using household information.

The household number itself was intended to provide the bridge between data files to support data mining and householding efforts. Data discovery software prompted the following questions that had to be answered to ensure correct data integration of these files:

- do the two sample data files include the entire household file

- has the household number (important identification and matching data) been captured correctly for each file

- was the extract, transform, load of source data performed correctly to produce the sample data files to be used for analysis?

After data quality issues were identified and handled, the integration endgame began - mapping the source data to the target data definitions. In this case, the target was a set of tables for a data mart (a data warehouse subset or view) built using IBM's Insurance Information Warehouse (IIW) industry data model. Once defined through its data model customisation, the target IIW data mart was loaded into Fixed Target Mapping to prepare for the 'drag and drop' mapping of similar data fields between source and target data models.

Fixed Target Mapping software was demonstrated using the InsureCo agent and vehicle source data files. The actual mapping is a quickly learned 'drag and drop' method. Software is used to analyse the data and data formats being matched from the source to target mapping process. The results of the interactive assessment by the analyst using this software are given in Table 2 .

\section{BUSINESS ISSUES}

Two significant initial discoveries were found to be dependent on the questionable data quality in all source data files:

- there could be a negative effect on the delivered product-pricing model, the accuracy of which is critical for the sales campaign

- there could be an effect on accurate decision making and the ability of the data to support the market segmentation analysis needed for each sales campaign.

These discoveries had significant business impact. The activity of profiling the data and identifying irregularities and possible quality problems opened up communication between technical teams and business users about the data and their intended use and effect.

The team achieved two important results:

— identifying incompatible fields and identifying source fields where the 


\section{Customer data management in practice: An insurance case study}

Table 2: Results of interactive assessment

\begin{tabular}{|c|c|c|}
\hline $\begin{array}{l}\text { InsureCo source } \\
\text { Agent Table } \\
\text { attribute code }\end{array}$ & $\begin{array}{l}\text { IIW target Agent } \\
\text { Table attribute code }\end{array}$ & Data mapping discoveries and comments \\
\hline Status & Status & $\begin{array}{l}\text { Appears to be an incompatible target definition based on } \\
\text { 'unknown' data type specification. Note: the data description } \\
\text { language used to generate the target database generated a } \\
\text { character (8) specification based on a 'small code' data type } \\
\text { definition in the logical model that was inconsistent with the } \\
\text { input. Where there are apparent differences in data } \\
\text { descriptions for source and target data models, the analysts } \\
\text { must decide which data format is appropriate and either } \\
\text { change the target format or specify a transformation rule to } \\
\text { be part of the ETL process. }\end{array}$ \\
\hline Sex & Gender & $\begin{array}{l}\text { Gender is specified as extended } 254 \text { length. Target definition } \\
\text { appears to be incomplete. }\end{array}$ \\
\hline Agent & Agent number & Valid match. \\
\hline $\begin{array}{l}\text { Sclscrty (Social } \\
\text { Security Number) }\end{array}$ & $\begin{array}{l}\text { SSN (Social Security } \\
\text { Number) }\end{array}$ & $\begin{array}{l}\text { Noted that SSN is being stored in } 2 \text { different target locations. } \\
\text { For example, SSN and tax identification. According to an } \\
\text { IBM analyst, it was apparent that InsureCo had not reviewed } \\
\text { all IBM IIW attribute names for standard abbreviations } \\
\text { guidelines (which help cross-system consistency) or } \\
\text { determined whether this data redundancy (two target fields) } \\
\text { was necessary. }\end{array}$ \\
\hline Sclscrty & Tax identification & See note above. \\
\hline $\begin{array}{l}\text { InsureCo source } \\
\text { 'Sub of ins' } \\
\text { Vehicle Table } \\
\text { attributes }\end{array}$ & $\begin{array}{l}\text { IIW target Vehicle } \\
\text { Table attributes }\end{array}$ & Data mapping discoveries and comments \\
\hline $\begin{array}{l}\text { Insurance } \\
\text { subject ID }\end{array}$ & Vehicle identification & $\begin{array}{l}\text { Incompatible lengths eg } 10 \text { vs } 5 \text {. Need to refer back to the } \\
\text { list of domain values for SOI (subject of insurance) ID } \\
\text { because the domain values don't appear to support the } \\
\text { assumed simple transform rule resolution. }\end{array}$ \\
\hline Model code & Car model code & $\begin{array}{l}\text { Incompatible lengths and data types. For example, integer } 5 \\
\text { vs character } 4 \text {. Further compatibility analysis required. }\end{array}$ \\
\hline $\begin{array}{l}\text { Garaged at night } \\
\text { indicator }\end{array}$ & None & $\begin{array}{l}\text { The IBM IIW target does not have this field. According to the } \\
\text { IIW analyst, the IIW data model design accounts for this by } \\
\text { relating the vehicle object to the garage object. However, no } \\
\text { single attribute physical indicator is overtly defined in IIW. If } \\
\text { InsureCo will need this as an indicator, new attribute is } \\
\text { needed in the customised target IIW model. Such local } \\
\text { customisations are common and easy to apply, but would } \\
\text { not form part of a generic reusable model such as IIW }\end{array}$ \\
\hline Purchase price & Acquisition cost & $\begin{array}{l}\text { Incompatible data type definitions. For example, integer vs } \\
\text { money. }\end{array}$ \\
\hline $\begin{array}{l}\text { Vehicle } \\
\text { identification } \\
\text { number }\end{array}$ & Vehicle identification & Valid match. \\
\hline Make name & Car manufacturer name & Valid match. \\
\hline
\end{tabular}

target field had been missed

significantly improved the accuracy of the extract-transform-load (ETL) and mapping requirements

- for data elements that did not exist or could not be easily corrected, the team set and managed the expectations of the business sponsor on how project results, and success, could be measured.

This analysis allowed the business sponsor 
to assess more accurately the options for operational data correction projects to support longer-term data quality efforts. The profiling findings identified that several source fields considered crucial to the mining process could not support this kind of analysis until data quality was improved.

Another result was an increased focus on data quality within the company. Now that the impact of poor data could be identified and addressed, the data quality effort on the next series of extracts from the source would be better and more accurate. The more recent data validation processing during the initial source extract would be better than that of the original converted files. For example, during the earlier data conversion for this project, some updates had been turned off to enable the loading of all data records and to allow for the introduction of derived default values. The impact of doing so had now been clearly demonstrated.

Despite identifying many data-related issues that could have a negative effect, the positive effects were:

- some data had been identified as good enough quality for analysis (although perhaps with limited remedial action). As data quality had been more clearly assessed, there was also better understanding of the reliability of analysis results

- some data were of too low a quality and needed to be excluded from analysis at this stage, with plans for funded attention later, which would be related to potential business value and returns

- acceleration of the project data profiling and mapping stages enabled more time to be allocated to the analytics development, eventually exceeding the original expectations of business reports delivered.

\section{DATA MINING ISSUES}

These included the following:

- the functional nature of the InsureCo data files directly affected data integration and data mining. For example, mortgage records did not have up-to-date age and value information associated with policyholders. Although these data were consistently maintained in car policy records, the ability to cross-sell effectively from mortgage to car was limited by the lack of age data in other files

- the profiling identified that some source fields might not support the type of data mining needed to drive a sales campaign based on the ability to correlate (from the data) the propensity to buy auto insurance with having high amounts of life insurance

- although the home owner data file was relatively clean, many of the fields were blank or unused. The project team had made the incorrect assumption that the data file could be used 'as is' for data mining. Once this was understood, remedial action could be taken (for example, using supplemental data from external sources or other systems, improving future data collection)

- the profiling process discovered that legacy file conversions ensured that the fields used for pricing were accurate but that many other fields that were derived or dependent on correct data input might not be sufficiently accurate.

\section{WHAT WAS DONE AND WHAT DELIVERED}

\section{Data assessment}

Early and accurate assessment of the multiple operational data sources enabled 
issues to be identified within the early stages of the project rather than 'in flight'. Some data quality issues were not relevant to this business use of the data and could be set aside until a later project required these data and could justify data quality improvement effort. An accurate assessment of effort, cost and elapsed time could now be made based on a rigorous and formal assessment of actual data sources. Actions could be noted against specific data issues and tracked through to full understanding and resolution. Considerable rework was avoided through achievement of such an early and complete understanding of the required data sources.

\section{Customisation of, and mapping to, the target data model}

Use of a mature industry business data model enabled rapid business requirements checklisting rather than an extended period of requirements definition. The target data model was formed through customising the industry data model provided by the consulting company. Customisation included the selection of relevant business areas and data structures for population with source data. Some data items would be renamed or specified to match InsureCo standards, however, in excess of 80 per cent model fit is expected. Subsequent project steps would select additional business areas of the model and would be expected to gain benefit from data (overlap) already made available through this phase 1 project. The reconstructed source data descriptions (meta data) could easily be mapped to this customised target data model. In practice, the project team were working on both source and target definitions simultaneously, however, the software used enabled the management of this continuing change process without confusion.
Extract, transformation and data load definitions and schedules were automatically created from the outputs of this data mapping exercise, effectively 'programming' the use of generally available ETL tools. Data quality improvements were specified in the same manner, allowing statistical assessment and transformation of specific data fields to be carried out in a continuous and automated manner. This approach supports efforts to maintain higher data quality once initially achieved. Of course supporting people, process and technology issues must also be addressed.

Business reports were generated to meet the agreed requirements of the business users. Due to the acceleration of the data preparation processes, more reports than expected were delivered within the time allowed for this project. The number, quality and value of business deliverables were exceeded in this manner.

\section{PRINCIPLES DEMONSTRATED}

In the authors' previous two papers on this topic, ${ }^{4}$ a number of important principles concerning the improvement of customer data were established. These principles are demonstrated by this case study in many ways, as follows: the completeness, appropriateness, accuracy and currency of data cannot be taken for granted. Serious work needs to be undertaken before a company can be confident that its customer data are ready for new applications:

- a comprehensive assessment of the state of customer data should be undertaken before improvement work is started, as this enables the company to prioritise its work

- if the company had focused at an earlier stage on the need for customer information quality, and developed a 
customer information plan and all that goes with it, including measures of data quality, it would probably not have needed to carry out such a project, but would have dealt with most of the issues within routine data maintenance activity

- the above would have been helped by a stronger focus earlier in the company's history on the use of customer data to generate value for both the company and its customers

- the lack of a culture of accuracy of data quality is one of the consequences of not understanding the long-term consequences for data quality of a wide variety of factors from systems development to the daily work of those entering and using customer data.

\section{SUMMARY AND CONCLUSION}

The software that was used clearly demonstrated its value in discovering previously unknown facts about the condition of the InsureCo source data. Perhaps more importantly, using these software tools to make these data discoveries, rather than using a more subjective or less rigorous approach, permitted an open and frank IT-to-business communication based on the actual facts about the data rather than speculation. For example, the ability to document accurately the quality of the data let the IBM and InsureCo team manage and set the business sponsor's expectations of the level of fine detail inherent in the data available for sales campaign initiatives, through support of planned data mining efforts. Moreover, the sponsor could assess better the options for improving data quality to support future campaign efforts. For example, what would it require for InsureCo to upgrade its data quality of source systems, operator processes and training, or validation programs to expected levels?

Data discoveries such as those mentioned above can prompt further research to determine how or if data distortions can and should be eliminated before data can be successfully used, for example, identifying data cleansing and ETL requirements rather than disguising the data and using them without regard to the impact of poor data quality on market segmentation analysis, data mining, sales campaigns and so on.

Without the exacting and meticulous data profiling made available by the use of the software tools, InsureCo would have made poor business decisions due to its incomplete understanding of source data, even after investing significant time and resources in this BI project.

Achieving ROI from CRM, Business Intelligence, compliance and other complex and multistage integration projects is tough. This research shows that many projects fail to complete or fail to deliver anticipated ROI. Applying appropriate 'data on demand' reusable methods and tools for data integration, customer insight and other related projects can now be estimated, managed and delivered faster and more effectively - ensuring earlier business value and success.

\section{References}

1 Such as the Client Information Integration System (CIIS). CIIS is IBM's 'real-time/operational single view of customer' (in fact of customer and related parties, including household, advisers, trustees etc). CIIS emerged from banking and insurance (and is now deployed in many of the largest banks worldwide) it can be deployed in any industry (eg telecommunications). CIIS retains the 'party' structure of relationships, key customer data that are independent of operational/legacy systems (eg total value, potential future value) and a contact log of all incoming and outgoing contacts across all channels. CIIS is the primary integration point across multichannels, it is to used to identify the customer and to support real-time marketing, sales and servicing operations. 
$2 \mathrm{BDW}$ is IBM's enterprise data warehouse (EDW) for banks. There are similar offerings for insurance (IIW) and telecommunications (TDW). The enterprise data warehouse combines data from channels, operational systems and supplementary data (eg external prospect list, geodemographic data, rating data etc) for analytics use. This provides the single and consistent view of the business by channel, by product, by customer, household or by any other dimension required. The EDW is the control point for analytics, it needs to be based on an industry data model to comprehend all the industry aspects relating to customer profitability, and in FS to compliance as well.

3 MQSeries and Crossworlds are IBM's data messaging systems, used to connect disparate channels, operational (legacy) and analytical systems in real time (or near real time). Standard (XML) message formats based on IBM's industry data models (eg FSDM for banking, or IAA for insurance) are used to provide consistency of message formats. IBM's Websphere Business Integration services combines and replaces both MQSeries and Crossworlds, including strong industry content for process management and workflow.

4 Stone, M., Foss, B., Henderson, I., Irwin, D., O'Donnell, J. and Woodcock, N. (2003) 'The quality of customer information management in customer lifecycle management', Journal of Database Marketing, Vol. 10, No. 3, pp. 240-254; Stone, M., Foss, B., Henderson, I., Johnson, P. and Murray, D. (2003) 'Managing the quality and completeness of customer data', Journal of Database Marketing, Vol. 10, No. 2, pp. 139-158.

\section{APPENDIX 1: COMMENTS AND RESULTS OF POST-PROFILING DURING DATA ANALYSIS SESSIONS}

'This tool allows us to make an informed design (of the data marts) - and we have not yet made an informed design in this project.'

'There are three data analysis/assessment options in a project:

1. Do the data analysis manually, attribute by attribute, relying on documentation, business analysts, data analysts and data dumping for input.

2. Do the data analysis through an automated process.
3. Don't do it and rely on assumed accuracy of operational data.

Number one is terrifically time consuming and fraught with error, number two is thorough, efficient, iterative and repeatable, but the software can be difficult to justify for single project use, unless special financing arrangements are made. Number three is project suicide.'

'Companies will say "what do you mean we don't know our data - of course we know our data!" but we really don't know it.'

'Evoke (Software) validates what you do know [about the data] and highlights what you don't know - and it is what you don't know that bites you.'

'The most common feeling when presented with the results of the functions of Evoke (Software) is disbelief.'

On access to the business and data subject matter expert:

- We can get them for an hour at a time; we can't get them for the blocks of time needed'

- 'There is never a complete substitute for this expert input but you have to deal with the reality that you often do not get them, if the project doesn't have the required management muscle behind it'

- 'If your business and data experts won't or can't participate, how do you know that the $(\mathrm{BI})$ analysis and mining results are any good? How can you possibly make a confident business decision based on the (BI) analysis and mining results unless and until you can trust (and can track and recreate) the input data?' 
On the agent file:

- profiling 69 attributes took 1.5 hours. From session with business subject matter expert: Q. Do you really have an agent number '00'? A. You know, I see that in every state and I always wonder what that means ....

- on making decisions about data that are obviously inaccurate but difficult to acquire or to validate and correct, ask the question, 'Is (the data attribute) a high priority cleansing item?'

- during agent file analysis it became apparent that the file was being used for more than just agent information, it was a holding area for other data that had no real home.

On the client file: (car and fire and some other policyholders outside of car and fire from the electronic billing system):

- profiling of 34 attributes took 1.5 hours. Household number is persons and 'interested parties', that is, financial institutions like mortgagors or finance companies (these should be shown separately from, but linked to, households to avoid confusion)

- client number is not unique within a household.

On the fire policy file: profiling 59 attributes took 1.25 hours.

On the auto policy file: profiling four attributes took one minute (0.017 hours).

On the property structure file: profiling 119 attributes took 55 minutes (0.912 hours).

- data led to some humorous questions from customer service personnel and others: Is your roof older than your building; Is your house sitting on a vacant lot; Does that vacant lot have a 'replacement cost' so you can rebuild it?; Was 15 per cent of our property insurance issued on buildings constructed during the middle ages?;

Were 65 per cent of our insured roofs replaced in 1997?

- 'If you had told me that I would have construction years in the 000s, I would have told you that was (nonsense). This is a new system, with good edits and data like that cannot get through! But I see that (some of) the bad data is in there.'

— 'The data stored is remarkably different from that collected.'

On discussing how to deliver the message of the assessed data quality to a primary project user/sponsor:

- 'I'm very anxious to tell him what we have discovered - in just one day - about the quality of the data that he is expecting to use from this project to make business decisions.'

- 'For us not to share the information that we have discovered with project management and with the executives who act for the benefit of the stockholders who are paying our salary is unthinkable.'

'This is the beginning of knowing, quantifying and correcting the data (in those cases where) the business can justify (correcting it).'

'The apparent inaccuracy of the data is a surprise to me.'

\section{APPENDIX B: PROJECT TECHNICAL DETAILS}

ETI Extract was used for data extractions.

Vality Integrity (now owned by Ascential Software) was used for data cleansing transforming and householding of 
customer data.

IBM Insurance Information Warehouse (IIW) was used as the basis for customised target data definitions.

InsureCo provided required test data to the IBM project team.

InsureCo ensured that the mix and distribution, volume, content and quality of the test data were satisfactory and representative of the data that will be in the production system.

Internal data will be updated monthly via ETL.

Data sources included: car, fire, agency, life, claims, financial and one external source. 